\title{
CRITICAL DISCOURSE ANALYSIS: THE KNOWLEDGE POWER PRESENTED BY SCHOLAR IN CREATING RESEARCH ARTICLE
}

\author{
Tisa Arum Wardani ${ }^{1}$ \\ Universitas Negeri Surabaya \\ Slamet Setiawan ${ }^{2}$ \\ Universitas Negeri Surabaya \\ Pratiwi Retnaningdyah ${ }^{3}$ \\ Universitas Negeri Surabaya \\ tisareog@gmail.com ${ }^{1}$ \\ Submit, 04-07-2020 Accepted, 22-12-2020 Publish, 29-12-2020
}

\begin{abstract}
This study was aimed to analyse the background study on research article and put the argumentation based on the theory about critical discourse analysis related to social cognition theory. Furthermore, the researcher wanted to compare 2 article in critical discourse analysis approach. This method on this study is descriptive qualitative which is presented in the positivist views. Then the result was generalized in the relation on finding and discussion with the theory. In summary, the result showed the different ways in giving the power of the argumentation and explanation between RA1 and RA2. In conclusion, the power of argument used will lead the reader to ignore or accept on how it is become valid statement or not.
\end{abstract}

Keywords: Social Cognition, Critical Discourse Analysis, Background Study

\section{INTRODUCTION}

Writing is a way people expressing the meaning trough written product. The writing product is a communication way that allows the reader to get the ideas, organize the beliefs and knowledge into convincing arguments. It also an expression as an art of work. Moreover, the writing categorized as academic major activity for academic purpose and non academic purpose. The academic writing for academic purpose refers to writing in area of academic such as writing paper, writing essay, writing thesis and so on, while the writing for non academic is more free in language use and structure. In proposing the writing in academic purpose, the writer should put the descriptive, argumentative, analytical and persuasion language that is not far away from structuring the term of the language use. As Hyland (2009) argued that writing skill will improve through practice, discussion and revision of topics in student interest. In four skills, Writing is 
regarded as the most difficult one. It requires the mastery of both theoretical and grammatical devices. It also requires the judgments and conceptual devices

As the theory that Widdowson (1998) points out, the related theory in such Critical Discourse Analysis (CDA) will present on how the text or passage give the power to persuade, put belief, acceptable element and the other elements relate to the ideological power that sometimes unseen. The discourse is representation of ideologically area, then the significance never be discovered. On the other hand, subjects (language user) put the argumentation as the power of the writing product. Critical approaches in language concerning with the maintain ways in which language in discourse reproduces social relations of power, Fairclough (1992).

Among power construction the theory presented meaningfully about how to divide the knowledge or believe into several categories according the strength. Some of knowledge, some times put the bias, some others are not. The Knowledge about knowledge present as the theory regarding the level of knowledge itself. Are the knowledge laudably claimed as knowledge, is that just a perspective by individual, is that believable among group or society, are the knowledge which are belief by many people in a society met the criteria on how knowledge is deserve as knowledge, and so on. Relating with those statements, Critical discourse analysis present the theory about how such unseen statement can be such the discourse in which categorized as implicit formulation. Van Dick, (1991) claimed that an essential part of an approach which is critically also play the vital role on relationship between knowledge and the social group. The task of some discourse analyst is for spelling out the power at the more detail of cognitive knowledge. Therefore, Social cognition define as the term relate to the possible integration between sociological and anthropological area.

While Background Study is one of the text part in research article, it become the reason why the study are important, necessarily, significantly, and useful for the reader to believe the text as an acceptable knowledge. A background is an overview on the background of the author persuasion statement, research gab, previous study, and reason study of the research article. The background have to be made from knowledge representation, the decisions presented authoritative and a sincere stance (Arrington \& Rose, 1987). The decision have to be made in strong argument and give the power in each statements. The background study also plays an important role for the writer to realize language power and on how the statement bring the strength in area social cognition or readers. Furthermore, a background study have to fulfill the intelligibility of knowledge cognition for the document representation. It should retaining the ideological representation of author mind with the strong power and truth. In Summary, The background act as the gate to scan the interest of the article. So that the background study is one of 
the most important part in giving such persuasive, provocative, and significantly in writing research article. In other word, the application of the knowledge become 'truth criteria' such as personal analysis and observation, for constructing knowledge: 'I know it, because I have seen, I have heard, I have observe and so on.

Along with the study about the Critical discourse analysis in writing, the previous study conducted the research in different way regarding those term. Gene L Piche (2015) conducted study entitled Social Cognition and Writing: Interpersonal Cognitive Complexity and Abstractness and the Quality of Students' Persuasive Writing. This study investigated the relationship between two individual differences in the quality and social cognition of eleventh grade students' in persuasive writing. This study analyzed writing product of a persuasive letter. The results showed a significant relationship between interpersonal cognitive complexity and abstractness quality of writing.

A common issue on writing research article are discussing about the textual and content of writing itself. Some of the unseen pattern such as on how the writer understand the writing, idea pattern manifestation, skills, knowledge about the structure and how they language engage her writing are rare. Some studies had been conducted those criteria are following. The Identity of the authors meanly declared the authors background. A study conducted by Kunnan (2019) mentioned that the agreement of his hypothesis is that background knowledge are needed and related with the writing performance. Since this study is mentioned just the background knowledge, it can be measure the background of the study. He missed to correlate the relationship between background knowledge and skills "How their background knowledge built their writing performance or skills in writing". The other issue on such background of the writing conducted by Thonus (2020). In his study, he investigated The disciplinary identity of Writing in Second Language. He mentioned the identity of the author is that how their writing relate with their field. The author who write the research article based on their study field became some beneficial in such give the writing performance in idea pattern. Meanwhile, the study investigated by Zhang (2018) mentioned the impact and relationship between language background and expertise in writing.

The idea pattern from the authors also mentioned in some previous study. The idea pattern is basically investigated the term in synthesizing theories in literature review session. As study created by Riazia (2016); Bruce (2018) were analyzing the literature review part reflected to the critical thinking and idea pattern. Those studies necessary to be more focus on what the theory reflected to the phenomena. In other hand, Asari (2018) focused on study about idea pattern on writing research article. The different ideas pattern presented by the author 
were vary. Some of the study also analyzing the language use as the representation on the weakness and the strength of research article writings. Such in the study investigated by Bradac (2015); Erikac (2019). Even the language content was investigated as subject discussion, the writer have to put some possible unexpected good writing performance not only because the language or word selection by the authors, but also the good and language power created by some prove reader of application that revised prominently.

The present study will investigate the research article background written by students in Post Graduate, Universitas Negeri Surabaya. This study analyse the background study on research article and put the argumentation based on the theory about critical discourse analysis related to social cognition theory. The social cognition relate with the knowledge belief by the social aspect perspectives, (Bar Tal \& Kruglanski, 1998). Therefore, this study, aimed to show how the chosen article create the ideological power in their research article background. This Study, also has purpose to accomplish analysis relating Critical Discourse Analysis (CDA) of on how the author use language to make his/her background study acceptable and believable among readers. The main goal of this ongoing research was to find the plausible answer regarding some question of research article publication that could be a good issue in analyzing the good background study in which has reputable in the sense of powering research article especially in using the ideological power.

\section{LITERATUR REVIEW}

\section{Critical Discourse Analysis}

The main of cultural science put the approach to a discourse presented by Foucoult, then developed by Jurgen Link and his team. Link (1990) defines discourse analysis is an institutional consolidation concept that consolidate the action and power. At the some times, discourse implies uninteresting topic regarding to the social practice, but it is merely to exercise the power and all its effects. Following the notion in critical discourse analysis, a discourse is represented the reality of the phenomenon in detail explanation. Relate to the theory of beliefs stated as the agent of knowledge, it will be valid just on the several times. Thus, the discourse giving the power on society area. In this belief, Foucault, (1978) argues that the knowledge should be categorized as the form of history analysis which report on the constitution of the subject that met the relationship between discourse, knowledge fields of object that occupy the criteria of acceptable knowledge among people.

The basic goal of discourse analysis is study of language, it was definitely by fairclough, that articulate on how language and power are related. Moreover the study about power and language can not be separate to the theory of society. 
Accurately, the discourse mention as the connections between language use and the power relations. The direction of discourse analysis has been called as language study. This also obtained as the dimension of critical language study, critical linguistics, critical language awareness and critical discourse analysis. Critical Language study, emphasize ways to analyzing language that can be oral or written text. Critical Language study was investigate relations how the language constitute and the power.

Critical Discourse analysis is grounding theories of language set that define language as the social factor and phenomenon (Halliday, 1978) and opposed the theories of biological and psychological phenomena (Clark and Clark, 1977). Therefore, Fairclough asumed that the human use the language to present the variation of social goals. He also argued that any analysis of language must be embedded with the social theory in which relate to the social practice in daily life.

\section{Knowledge and Social Cognition}

Some theorists claimed that social cognition is a central in composing the argument or describing in writing area. The area of Social Cognition and Writing has already sometimes become an opposed way in so many peoples. In the other word, in the discourse, social awareness is play important role in how the author or writer put the audience interest with those statement. A connection among writing and social cognition portray the myriad of audience-awareness research, Flavel (1985).

In the same ways, it would be described to reduce the knowledge as discursive, cultural or social phenomena. Gilbert and Wodak (2003) stated that knowledge is both association of neurological structures of the brain or cultural, as social factors, thus the association of the local interaction between the human society and global structures. It does not mean that the cognition is individual believe in their own perspectives. Although people has personal knowledge, or private knowledge, the social knowledge also present mostly in this world. The theory claimed about the knowledge that merge in wide social construction is called as social cognition.

Social cognition defined as the system in mental structures and shared by the member of group people, culture and organization. That system consisted of several system, such as attitudes, ideologies, values and norms, knowledge and the ways the structure or element that effect the society, discourse and social practice. Moreover, in the social psychology, social cognition is usually relate to the research tradition in the US, Taylor (1991). That approach generally occupied on having individualistic mind that ignores the beliefs of social dimension of the usage, knowledge and acquisition, Walker (1995). In other country such as 
Europe, work on shared language has been established in terms of social representation, Moscovici (2000).

Fortunately, there were attempts in integration between the tradition on a development that is in line with multidisciplinary framework. Therefore the use of social cognition is meaning in social aspect on social domain among cultural construction. Simply, the social cognition represent the combination of the cognitive and social aspect of knowledge and all stuff on social mind or social thinking, Flick (1998).

\section{Types of Knowledge in Relation with Written Text}

There such explicit formulation in area discourse-knowledge interface that requires a typology of knowledge. The Typology of knowledge define as variation of knowledge based on the knowledge level itself.

The typology of knowledge can differ on some division, Ruth Wodak and Gilbert Weiss (2003) mentioning the distinction of knowledge such as Declarative versus Procedural knowledge, Personal versus social knowledge. Furthermore, the social knowledge also divide into categories: Interpersonal, group, and cultural knowledge.

Firstly, Declarative knowledge is determined as the word "knowing that" or "explicit". Secondly, Procedural knowledge is implicit or knowing how. Thirdly, Personal knowledge is about the notion of "private". It require personal experience and use just only in personal action. Fourthly, social knowledge is shared knowledge that possible to accept among society. Interpersonal Knowledge is the knowledge that accepted by two or a few people, commonly in conversation. Group of Knowledge is the knowledge that accepted by the whole group, initially believed by the group of people, institution, particular profession, or a whole culture. Cultural Knowledge presented the knowledge that accepted by many peoples such as the nation, word knowledge, through mass media in a country, and universal knowledge.

\section{Research Article Introduction Writing}

Academic writing is the dimension of writing in academic area. In constructing the research article, not only report the data found, but also have to find the strong evidence in any particular arguments. The evidences may from the recent publish book length which are related to the study topics. Language can not be separate with the contents.

Introduction are known as the troublesome, near with the difficulties among academic writers. They difficult to start and brainstorm the initial research article. The Introduction is the initial stages to arrange the academic writing in research article paper and others. The student need to exaggerate the opening, the 
reason, the concept, subject, previous study, gulf and so on in very simple way and interesting. As Swalles (2008) suggested that the introduction have to fulfill some criteria. Firstly, the decision of the background of the study. It refers to question about why the study is important?. The background of the study is the main reason why the study is important, the previous study related, the gulf and etc. Secondly, The introduction have to fulfill authoritative and sincere stance decision, Arrington and Rose (1987). The strong argument and sources are the element of the authoritative and sincere stance decision. The strong sources and believable language will provoke and persuade the reader in academic area of the research article paper. Decision must be made about winsomeness to appeal the readership. Lastly, the decision have to be made clearly and simply. The directness of such writing product in academic writing is a crucial element. The three element suggested by Swalles (2008) above will build the first assumption and impression matter of brief catalogue on Research Articles. One possible concept of Research paper introduction is Problem-Solution texts. Zappen (1983) argued that the writing in academic purpose related with the intellectual discipline that is located.

\section{RESEARCH METHOD}

In this study, Gillbert Weiss and Ruth Wodak divided the knowledge in such: 1) declarative Knowledge : the knowledge about "knowing that" that explicitly stated, 2) procedural Knowledge : the knowledge about "Knowing how" That implicitly stated, 3) personal knowledge : sometimes called as private knowledge, personal think, 4) social knowledge : a) interpersonal knowledge (two or a few people believes), b) group knowledge, (accepted by a group of people in same profession, institution, and organization, c) cultural knowledge is the beliefs accepted by many people such as the country nation. The researcher investigated the background study written by selected Journal Article based on theory above.

The researcher analyzed 2 Research Article written by two post graduate students,in Pendidikan Bahasa dan Sastra, Universitas Negeri Surabaya, Batch 2018. The Research article was the task in the major pragmatic-stylistic assignment in the second semester. The research article selected randomly. In discursive study, the comparison between two discourse can be seen as the interest views, since the correspond to the same institutional. (Faucoult, 1978).

Several checklist was designed by the researcher that correspond to the theories by Gilbert and Ruth Wodak (2001) 
Table 1 Type of Knowledge

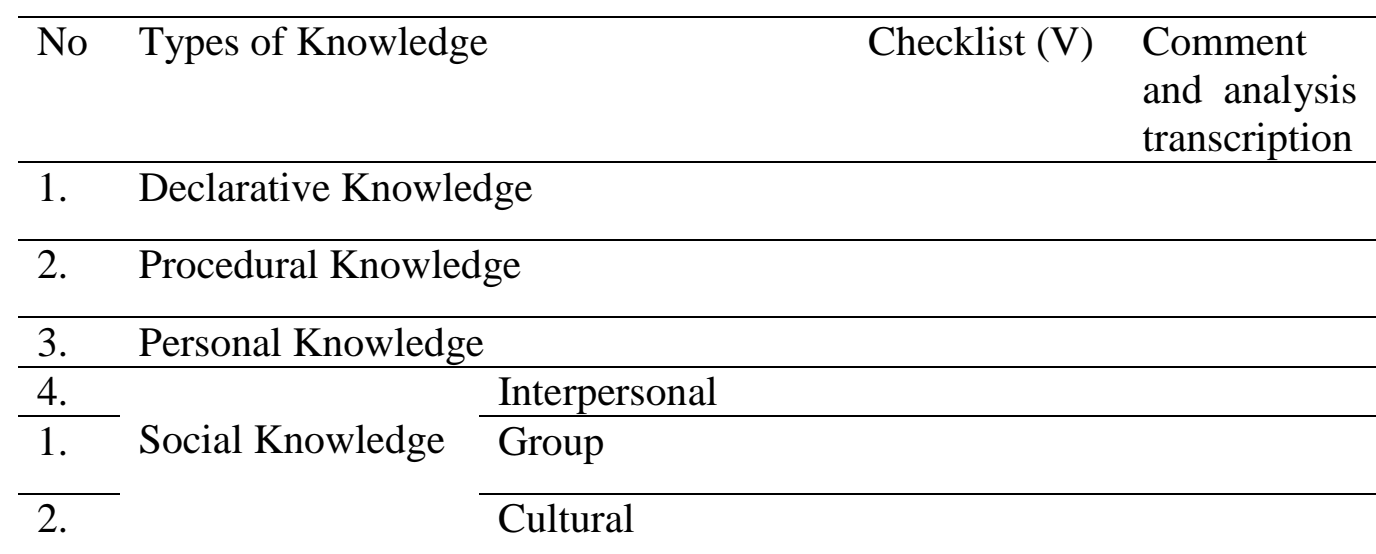

Adapted by Gilbert and Ruth Wodak (2001)

The table was designed to examine features of knowledge regarding to the chosen articles. The theoretical discussion that proposed in the following categories such Discourse is societal flow that investigate the texts represent the complex and art series. In order to address the several themes and that is deal with the several themes (Micheal Meyer, 2001). Moreover the analysis used the perspectives of Entanglement of Discourse strands and discursive context in which the text are issued by the academic writing and it's contextually in the same topic discussion.

\section{FINDING}

\section{The Knowledge Presentation on Ist introduction in RA 1}

The first introduction research article (RA1) presented various type of knowledge. Here are the explanation which are showed in detail explanation based on the whole paragraph.The presentation on the sentences showed in detail explanation related to the theory used with the real sentences. The introduction from the RA1 has the big portion on the declarative knowledge, and group knowledge, even the other type of knowledge also presented on it. The author of $\mathrm{R} 1$ give the sentences in such the sentence below:

The great changing in technology leads people to have new style on communication.

That statement presented the declarative knowledge since the word changing in technology is kind of information that is want to declare on the reader. The reader get the information about the movement of technology. As the theory of the strength of the information, the declaration that the RA1 author here is not truly the fact, it just the personal knowledge. The personal knowledge can 
be seen in that statement in which there is no evidence. It can be seen as the transformation that is can not say as changing. This word is possibility refers to other several meaning. In the other finding, the personal statement also portrayed on the sentences below.

Nowadays, people is more likely to communicate virtually through Social Network Sites (SNS).

Since the statement stated the phenomenon that recently happen nowadays, there still the possibility people to communicate is not using the social network. It refers to the declarative that believed by many people as the truth. But it is not in a massive people. The truth is kind of social knowledge that are naturally acquire among society based on the something seen. Beside it is a personal knowledge, it also refers to group knowledge in possibility. However, the believe of many people without the real evidence or data, will be still questioning.

The author in RA1 seems explained so many sentences, even it is not many theory citation uses, she stated and claimed based on her perspectives. Even the perspectives are the fact, the power of that statement is necessarily to create. However, the research article is kind of academic writing that is not good in using some bias perspectives. Here is the other sentence on RA1 introduction.

It is essential to identify the speech acts used in Social Network Sites (SNS) since the virtual communication lead people to have different reaction on the written text.

In addition, identifying the speech act is the work for people who has the background knowledge on linguistics. It is kind of profession or institutional believe that refers to the group of people. Therefore, the believe of speech act meanly shared by the RA1 author to present the procedural explanation, since the cause and effect portrayed on the word "since". Virtual communication improve so many people to build the different views about statement. The term speech act, initially the term in the area of linguistics, even it is part of the linguistic major discourse, it is quite possible to know for many people in all major. In sum up, here is the knowledge believe or accept and acquire in the group of people, but it is possible to share for all people space. Sometimes the declaration of something portraying the ambiguity. The sentences below quite bring the multiinterpretation.

The rapidly changed in technology with its easiness, it leads people to have drastic transformation in communication. 
The change of technology development can be seen as many people in this world. So that, those phenomena was acceptable on group of people in some region, area, or country. However, the traditional area that is not became the technology change area will presuppose the technology as the difficult one to access. The word "easiness" will bring many possible meaning. The easiness on what, the easiness on ho, and so on. So that it can not be refers as cultural knowledge, even though the writer want to inform or declare the information. Fortunately, in sharing statement that is label as "knowledge" in the theory has explained, the author also create some comparison.

People is more likely to communicate virtually than by reality or face to face in recent times. Furthermore, technology has provided new Medias that lead people to be interested in technology.

In that statement, the author want to share the knowledge which are commonly know among peoples. The people know about the use of technology, but it is still refers to the personal knowledge in the personal thinking of the author. She opined that more people commonly use the virtual communication using online media rather than face to face conversation. Based on the statements above, it is not line with the reality. The realities is that people generally used face to face conversation in their home, workplace, school and many more. The use of technology can not be claimed that has big portion among people in the world to do communication. Eventhough many sentences used such personal and declarative knowledge, the author also present the citation in the small portion. Here is the example on th sentences:

One of media that most people interested in is Social Network Sites (SNS) (Nartey, 2013)

In that statement, the author present the information refers to declarative knowledge, since she portrayed the fact of people interest. It can be seen as the personal knowledge and interpersonal knowledge. The personal author take in mind that the social network site is part of interesting tools among peoples. It can not claimed like that, because the possible claim will vary. The word interest can be possible change as the need of many people. It also possible in opine as the movement that so many people want to be part on it, even actually some people is not too interest on it. Among citation Nartley (2013) and the author have the same opinion, so that it refers to interpersonal knowledge. The combination of the level of knowledge in presenting declarative and cultural knowledge had portrayed in those statements. 
"One of the popular Social Network Sites (SNS) is Instagram"”'Instagram is social network sites to capture and share the world's moment"

Instagram is trully one of the social network sites. Even the author of RI didn't explained about the evidence or something to create believe among readers, the fact that is truth categories is the cultural knowledge. Since the cultural knowledge refers to the possibility people accept those kind of explanation or knowledge. The declarative sometimes put the bias statement. Not all people easily to look activity in others people. Not all people using instagram. Not all people love to visit instagram. Here are the sentences regarding to the explanation.

Now, people can easily look at other's people activity by Instagram since they may share their activity by stating the place, time and also picture.

The author of RA1 also presenting the procedural and personal knowledge based on no evidences, below.

Caption can lead people to comment on the posted photo. Caption has meaning that can attract other user of Instagram who read the caption attract on it by giving comment.

The procedural sentences presented on some sentences citation. The word "so", here has the meaning of procedural. There is relationship between the first and second language as the cause effect. Here is the sentence:

Pragmatic is the study of context. In a context, people may have variant meaning and it does not only have one single meaning for all readers, so reader may have their interpretation that is different each other (Black, 2006, p. 2).

Caption provided people to do speech act since the speech can act to the followers and make them to be interested in with the caption by giving comment on it (Nuramila, 2016).

Speech act is the communicative meaning of an utterance to perform in the definite social context (Chinelo J, 2015).

Those sentences refers to the explanation of group knowledge of people in which refers to area linguistic and pragmatics.

In summary, the RA1 author presenting the variation of knowledge in her research article. The variation bring the power of knowledge itself. There such many personal perception rather than procedural and citation format from the 
other sources. The use of personal knowledge on writing academic in a big portion refers to the low guarantee of the strength among readers in area social cognition acceptance.

\section{The Knowledge Presentation of Introduction in RA2}

The second article (RA2) presented knowledge in her writing product not vary. The procedural knowledge that are present in the evidence lead the RA2 author bring the strong argumentation. The sentences on how the author explained is acceptable since the citation of the theory, previous study are dominated in her RA2 writing. There such the little of personal knowledge in her introduction, as presented below.

Learning English as second language (ESL) is a crucial thing for some students in Indonesia. It is proven that it has becomes the main subject from elementary to the university level.

The selection of word "crucial" is that presented the personal interpretation. Initially, the RA2 author did not mention the evidence among the term "crucial". This also refers to declarative knowledge that share to the readers. The other sentences, as the initial stage to formulate the knowledge became the acceptable among schoolar. The RA2 author mention the experts to create strong evidence and prove her argumentation.

As ESL learners, they face some difficulties toward the skills in English such as reading, listening, writing, and speaking. Among those four skills, some experts stated that writing emerges as the most difficult one.

Furthermore, the RA2 author used the citation and paraphrasing the theories from many experts. Here is the following sentences.

Younes \& Albalawi (2015) argued that the writing difficulty is in form of creating a coherent and extended piece of writing and sometimes make students suffer from "writers' block".

She did the compare and contract the theory among expertise. The citation and the evidence here initially understood by the expertise's regarding to the topic discussion field. The particular field, is also the linguistic area. The group of people who understand the term in such speech act, feedback, ELT and so on are the formulation of knowledge is that commonly used by the schoolar in area education field and linguistics field. Eventhough the discussion is acquired in their area. The author of ra 2 means to share such group knowledge to al readers in particular ways in strong argumentation. Here are the example on it. 
In this case, Harmer (1983, p.326) stated that students have to follow various stages the way the writing is, such as pre-writing (drafting), editing, revise, and finally composing a finished version of their work. In addition, Brown $(2004$, p.335) also illustrated that written products are often the results of thinking, drafting and revising procedures which means that there are things to be prepared in each stage the students have. Thus, having a feedback from the teachers is needed for them before having a complete writing text. Some experts have conducted many different studies about writing feedback in English Language Teaching (ELT) field. Vardi (2012) propose a study that examines the students' writing characteristics and the way they change it after getting teacher's feedback and the occasion the next phase to rewrite. By referring to the methodology, the author gained the data from Australian university students in which English has become their first language

The RA2 author tend to formulate the argument with the theoretical explanation rather than personal knowledge that is part of bias. In some previous study, she also presented the theory related to the topic discussion in term of group knowledge, procedural, declarative, and also cultural knowledge. Among knowledge that she presented give the big portion on the social cognition acceptance.

Moreover, the author RA2 presented the gaps among other study. The other study is concerned with the serial research related to the topic discussion. In analyzing those phenomenon, the RA2 draw the present study as the result of review on how the research study should be. The knowledge is kind of serial knowledge that is present on the group of people or can be as the knowledge that is share on public space, even it is from journal article or not. The research article is presented more likely into very strictly explanation based on the theories rather than the media online or others.

\section{DISCUSSION}

\section{Comparison between RA1 and RA2}

The social cognition present on how the research article is reputable or not among readers, what kind of statements present on it, how many real data, how authentic they are. Narrowly, the unseen perspectives was created on the RA1 and RA2. The social cognition based on the theory presented in Ruth Wodak and Weiss (2003) has presented in the RA1 and RA2. In RA1 the variation on personal knowledge portrayed in big portion based on phenomena. Using the positivist views on qualitative characteristic in methodology in research article, the researcher draw is that based on the data present between RA1 and RA2 vividly different. Etymologically, There is no statistically means. Moreover, it reflected causal relationship among elements of reality and summarizing into 
generalized finding. However the RA2 has many evidence in sharing knowledge in her Research article. There so many explanation on giving the argument, declare, procedural idea and formulate it into real gap from the previous study.

The knowledge power will present on how the research article are acceptable or not in area social cognition. The RA1 portrayed the formulation on sharing knowledge trough Knowledge on declarative, personal, interpersonal, cultural, and group. Fortunately, lack power in cultural knowledge and group knowledge with no evidence presented, will lead to unbelievable knowledge among readers. Meanwhile there are a few formulation on knowledge of bias in RA2, it presented many evidence to prove the arguments in RA2. The cultural knowledge, the group knowledge are presented on the RA2 introduction. Even though the RA2 presented the various of knowledge that reach on evidences, it still has a personal perspectives in the starting statement.

\section{CONCLUSION}

The knowledge on theories consisted of 6 knowledge categories based on Wodak, 2003. Those article present the argumentation in different ways. Fortunately, based on the power of argument used will lead the reader to ignore or accept on how it is become valid statement or not. In reading article, the reader will accept the argumentation, description, explanation, and so on based on the knowledge criteria, that sometimes is not seen. The critical discourse analysis has been presented on the generalization views in analyzing academic Research Article 1 and Research Article 2. However, the strong argument is that the sentences in which give the evidence from the theory among experts such presented in RA2. Since the introduction in the article is the writing academic which is not part of literature review, it has possibility to bring the argumentation based on the researcher perception, the group knowledge perception in field area (expertise), or maybe cultural knowledge, but it have to consist of possibility and logically for social cognition. In area of academic writing, the strongest argument is that article in which give the evidence among statements that present the knowledge of academic field. The evidence lead the research article became ideologically accepted by the group of major people. The current study of introduction power lead the reader to implement the strong argument for the next research writing, especially in writing the introduction. 


\section{REFERENCES}

Arrington \& Rose. (1987). Prologues to What Is Possible: Introductions as Metadiscourse.

Asari, S., \& Kurnia, F. D. (2018). Ideas Pattern Manifested in Rhetorical Moves of English Language Teaching and Learning Research Articles Discussion Written by Indonesian English Academics, 1(1), 83-92.

Bradac, J. J., Hemphill, M. R., \& Tardy, C. H. (2009). Western Journal of Language style on trial : Effects of " powerful" and " powerless " speech upon judgments of victims and villains, (January 2015), 327-341. https://doi.org/10.1080/10570318109374054

Bar Tal \& Kruglanski, 1998. Sociological Foundations of Interactable Conflicts Research Article https://doi.org/10.1177/0002764207302462

Bruce, I. (2018). English for Speci fi c Purposes Expressing criticality in the literature review in research article introductions in applied linguistics and psychology. English for Specific Purposes, 36, 85-96. https://doi.org/10.1016/j.esp.2014.06.004

Cai, Y., \& Kunnan, A. J. (2019). Detecting the Language Thresholds of the Effect of the Background knowledge on an LSP Reading Performance: A Case of the Island Ridge Curve. Journal of English for Academic Purpose, 42, 1-32

Clark, Herbert H and Eve V. Clark. 1977. Psychology and Language. New York: Harcourt Brace Javanovich.

Dick, Van. (1991). Elites, Racism and the Press. Oxford University Press

Erikac (2019). "Can We Agree on that? Plurality, Power and Language in Participatory Research. Sweden.

Fairclough (Ed.), (1978). Critical language awareness (pp. 223-237). London: Longman.

Fairclough, N., \& Longman, L. (1997). Critical Discourse Analysis : The Critical Study of Discourse Analysis, 104-112.

Fiske, S.T., \& Taylor, (1991). McGraw-Hill series in social psychology.Social cognition (2nd ed.). Mcgraw-Hill Book Company.

Flavel (1985). Cognitive Development. University of Michigan

Flick (1998). The Role and Contribution of Narrative Interviews in Educational Research. Gordon College of Education. American Journal of Educational $\begin{array}{lllll}\text { Research. 2017, Vol. } & 5 & \text { No. } & 4, & 419-427\end{array}$ DOI: $10.12691 /$ education-5-4-10

Gilbert and Ruth Wodak (2001). Methods of Critical Discourse Analysis, Vol.1, DOI: $10.4135 / 9780857028020 . d 4$. Sage.

Halliday, D \& Resnick, R. 1978. Psychology and Language. New York: Harcourt Brace Javanovich.

Hyland. (2009). Academic Discourse: English in a Global Context. London: Continuum

Moscovici (2000). Ideas and their development: A Dialogue between Serge Moscovivi and Ivana Markova. Polity Press: Exploration in Social Psychology

Riazi, M., Shi, L., \& Haggerty, J. (2018). Journal of Second Language Writing Analysis of the empirical research in the journal of second language 
writing at its 25th year ( $1992-2016$ ). Journal of Second Language Writing, 4l(December 2017), 41-54. https://doi.org/10.1016/j.jslw.2018.07.002

Swales, J (2008). Genre Analysis English in Academic and Research Setting. Cambridge University press. United Kingdom.

Thonus, T. (2020). Journal of Second Language Writing The Disciplinary Identity of Second Language Writing. Journal of Second Language Writing, 49(February), 100725. https://doi.org/10.1016/j.jslw.2020.100725

Walker (1995). Personality Correlates of Depressive Style in Autobiographies of Creative Achiever. https://doi.org/10.1002/j.2162-6057.1995.tb00738.x

Weiss, G \& Wodak, R. (2003). Critical Discourse Analysis: Theory and Interdisciplinarity. Palgrave Macmillan.

Widdowson. (1998). Language and Culture. Oxford: Britannia

Zhang J, et al. (2018). Learning Nucleosome Positioning from DNA Sequence with Improved convolutional Neutral Networks. 